\title{
Randomized controlled study comparing clinical outcomes after injection botulinum toxin type A versus corticosteroids in chronic plantar fasciitis
}

\author{
Prakash D. Samant, Sachin Y. Kale*, Sohrab Ahmed, Adnan Asif, \\ Mahena Fefar, Shikhar D. Singh
}

Department of Orthopaedics, DY Patil Medical College, Navi Mumbai, Maharashtra, India

Received: 09 April 2018

Accepted: 10 May 2018

*Correspondence:

Dr. Sachin Y. Kale,

E-mail: sachinkale@gmail.com

Copyright: (c) the author(s), publisher and licensee Medip Academy. This is an open-access article distributed under the terms of the Creative Commons Attribution Non-Commercial License, which permits unrestricted non-commercial use, distribution, and reproduction in any medium, provided the original work is properly cited.

\begin{abstract}
Background: The plantar fascia is a common condition, for which there is no consensus on the best treatment option. The aim of this study is to compare the pain and fascia thickness outcomes of patients treated with botulinum toxin $\mathrm{A}$ injection versus corticosteroids injection.

Methods: 50 patients of plantar fasciitis randomly received injections of either botulinum toxin A (100 units in $2.5 \mathrm{ml}$ normal saline) or methylprednisolone $(2 \mathrm{ml}$ of $40 \mathrm{mg} / \mathrm{ml})$ under ultrasonographic guidance. Patients were assessed for pain using the visual analogue scale (VAS) and fascia thickness at baseline, 1 and 3 week, 3, 6 and 12 months post injection. Patients in the two treatment groups were compared for pain scores and thickness at each follow up.

Results: There were no significant differences in the patients in both the groups at baseline. Patients in both the groups had significant improvement in VAS pain scores over a 12 months follow- up. At the end of the study (12 month follow up), the VAS pain score was significantly lower in the group of patients who received botulinum toxin A $(1.68 \pm 0.62$ vs. $4.72 \pm 1.02$, p value $=0.001)$. There was a significantly less plantar fascia thickness in the group of patients who received botulinum toxin as compared to those who received corticosteroids at the 3 week, 3 month, 6 month and 1 year follow up.

Conclusions: Better clinical outcomes were observed with botulinum toxin type A as compared to corticosteroids. Similar studies need to be replicated with larger sample sizes before this can be offered as a standard treatment for plantar fasciitis patients.
\end{abstract}

Keywords: Botulinum toxin, Outcome, Plantar fasciitis, Pain

\section{INTRODUCTION}

The plantar fascia is a common condition in which a fibrous aponeurosis begins at the plantar medial calcaneal body, spreads over the plantar midfoot, and then divides distally to attach at the plantar aspect of all five proximal phalanges. ${ }^{1}$ It is frequently seen among sportspersons, accounting for more than $25 \%$ of disorders of the foot in athletes. $^{2}$ In general population, plantar fasciitis is responsible for $7 \%$ of cases of foot pain in the population over 65 years of age. ${ }^{3}$ The first line of management is conservative, which includes nonsteroidal antiinflammatory drugs, corticosteroid injections, cast or controlled ankle motion boot immobilization, night splinting and therapeutic exercise. Less common nonoperative methods have been attempted in past with some success like extracorporeal shock wave therapy and platelet-rich plasma injections. ${ }^{4,5}$ But the evidence is insufficient to support its widespread use among the patients. Operative management procedures like plantar 
fascial debridement and release have been suggested by some authors but are accompanied with inherent risks of surgery. ${ }^{6,7}$

Some authors have explored the use of botulinum toxin type $\mathrm{A}$ in the treatment of plantar fasciitis. ${ }^{8}$ This drug reversibly inhibits pre-synaptic release of primary neurotransmitters like acetylcholine and secondary neurotransmitters like substance P. Inhibition of acetylcholine causes muscle weakness and decreased substance $\mathrm{P}$ may provide analgesia. ${ }^{9,10}$ The aim of this study is to compare the pain and fascia thickness outcomes of patients treated with botulinum toxin A injection versus corticosteroids injection.

\section{METHODS}

\section{Study design and setting}

A double blinded randomized controlled study was performed in the Department of Orthopaedics, D.Y. Patil Medical College, Nerul, Navi Mumbai to compare the efficacy of botulinum toxin A and corticosteroid in the treatment of plantar fasciitis. Ethics approval was obtained from the human research ethics committee of D.Y. Patil Medical College.

\section{Sample population}

A total of 50 patients of plantar fasciitis were enrolled in the study from November 2015 till July 2017. Included patients were over the age of 18 years, diagnosed with painful heel by clinical examination, with the following positive clinical signs: pain in the morning 'first step' or after sitting for long time, local tenderness over anteromedial calcaneal tuberosity where plantar fascia is attached, increasing pain with extended walking or standing for more than 15 minutes, history of 3 months of unsuccessful conservative treatment. We excluded patients who had a previous surgery for plantar fasciitis, had infection or tumors of lower extremity, had hemorrhagic disorders and took anticoagulant therapy, were pregnant or lactating, had a known allergy or antibodies to Botulinum toxin A, known muscle disease or disturbance of neuromuscular transmission. Women of childbearing age without adequate contraceptive protection, those with history of diabetes mellitus or unwilling to participate in the study or not giving consent for the same were excluded as well.

\section{Study procedure and data collection}

The patients were randomly allocated to one of two arms (botulinum toxin A or corticosteroid arm). Written, valid and informed consent was taken prior to the injection. The patients as well as the examining doctors were blinded to the treatment given. Before administering the treatment, complete blood count, erythrocyte sedimentation rate, c-reactive protein, fasting blood sugar and X-ray of calcaneum lateral view were noted for all patients. Demographic and baseline pain score using the visual analogue scale (VAS) was noted. One group of patients received botulinum toxin A 100 units mixed with $2.5 \mathrm{ml}$ normal saline and the other group of patients received $2 \mathrm{ml}$ of $40 \mathrm{mg} / \mathrm{ml}$ methylprednisolone mixed with $2 \mathrm{ml}$ of $2 \%$ lignocaine. All injections were administered by the principal investigator under the supervision of senior orthopedician, using full aseptic precautions under ultrasonography guidance with the help of Department of Radiology. Plantar fascia was identified with ultrasonography and thickness was noted. Under visualization of ultrasonography, 25-gauge 1.5 inch needle was inserted from medial aspect of calcaneal tuberosity. The needle was visualized as a linear object with high echogenicity and the needle was further inserted until the maximum thickness of plantar fascia was found. For corticosteroid arm, $2 \mathrm{ml}$ of $40 \mathrm{mg} / \mathrm{ml}$ methylprednisolone mixed with $2 \mathrm{ml}$ of $2 \%$ lignocaine solution was used and injected in to the plantar fascia under ultrasonography guidance.

All patients were admitted and given non-steroidal antiinflammatory agents, analgesics and antacids for 5 days. All the patients were instructed on gentle stretching exercises for plantar fascia according to Department of Physiotherapy. And all the patients were instructed to remain non-weight bearing on the day of the procedure and then return to weight bearing as tolerated from the first day post-injection. All the patients were followed up at 1 week, 3 weeks, 3 months, 6 months and 12 months post injection. VAS score and plantar fascia thickness by ultrasonography were measured in the outpatient department of Orthopaedics and Radiology, D.Y. Patil Medical College. Additionally a clinical history and examination was conducted to assess for local and systemic complications such as infection, unremitting pain etc. All non-responders were telephoned to attend the regular follow-ups.

\section{Data analysis}

Data were analysed using the SPSS version 15 software platform. Quantitative data were described as mean and standard deviation and qualitative data were described as frequency distributions. Mean VAS pain scores and mean plantar fascia thickness of the patients in the two treatment groups at follow up visits were compared using the Mann-Whitney U test. A p value of less than 0.05 was considered statistically significant

\section{RESULTS}

Patients in the group receiving botulinum toxin A had a mean age of $43.9 \pm 6.52$ years (range 34 to 56 years) and that in the group of patients receiving corticosteroid was $43.3 \pm 6.84$ years (range 33 to 53 years). The mean duration of symptoms was $6.94 \pm 0.82$ months and $7.14 \pm 0.75$ months in botulinum toxin $\mathrm{A}$ and corticosteroid group respectively. All patients completed the follow-ups as there were no drop-outs from the study and no cross-over. Patients in both the groups had similar baseline characteristics (Table 1). There were 28 patients affected on left feet and 22 patients affected on right feet. 
There was no statistically significant difference between the subgroups with respect to any co-morbidity as well. Patients in both the groups had significant improvement in VAS pain scores over a 12 months follow- up. The VAS score was significantly higher in the corticosteroid group at 1 week follow up visit and significantly lower at 3 month follow up visit as compared to botulinum toxin A group. At the end of the study (12 month follow up), the VAS pain score was significantly lower in the group of patients who received botulinum toxin A $(1.68 \pm 0.62$ vs. $4.72 \pm 1.02, \mathrm{p}$ value $=0.001$ ) (Table 2). There was decreased plantar fascia thickness in patients in both the groups. There was a significantly less plantar fascia thickness in the group of patients who received botulinum toxin as compared to those who received corticosteroids at the 3 week, 3 month, 6 month and 1 year follow up (Table 3). No serious complications were seen in the patients enrolled in this study with either botulinum toxin A or corticosteroid. Repeat injections were required in $12 \%$ of the patients. No surgical interventions were required post injection in either of the two groups.

Table 1: Baseline characteristics of patients with plantar fasciitis enrolled in the study.

\begin{tabular}{|lll|}
\hline & $\begin{array}{l}\text { Group receiving botulinum toxin } \\
{[\mathbf{n}=\mathbf{2 5}]}\end{array}$ & $\begin{array}{l}\text { Group receiving } \\
\text { corticosteroid }[\mathbf{n = 2 5}]\end{array}$ \\
\hline Mean age \pm standard deviation & $43.9 \pm 6.52$ & $43.3 \pm 6.84$ \\
\hline Gender distribution $(\mathbf{n})$ & & 11 \\
\hline Males & 9 & 14 \\
\hline Females & 16 & 13 \\
\hline Affected side (n) & & 12 \\
\hline Left & 15 & $7.14 \pm 0.75$ \\
\hline Right & 10 & \\
\hline Mean duration of symptoms (months) & $6.94 \pm 0.82$ & \\
\hline
\end{tabular}

Table 2: Comparing mean VAS pain scores in the two treatment groups at regular follow up.

\begin{tabular}{|llll|}
\hline Pre-operatively & $\begin{array}{l}\text { Group receiving botulinum toxin } \\
{[\mathbf{n}=\mathbf{2 5}]}\end{array}$ & $\begin{array}{l}\text { Group receiving } \\
\text { corticosteroid [n=25] }\end{array}$ & P value \\
\hline 1 week & $8.68 \pm 0.9$ & $9.12 \pm 0.78$ & 0.12 \\
\hline 3 weeks & $7.80 \pm 0.92$ & $7.10 \pm 0.85$ & 0.006 \\
\hline 3 months & $5.12 \pm 0.60$ & $5.00 \pm 0.70$ & 0.521 \\
\hline 6 months & $4.00 \pm 0.57$ & $3.52 \pm 0.51$ & 0.003 \\
\hline 1 year & $2.88 \pm 0.60$ & $2.60 \pm 0.64$ & 0.119 \\
\hline
\end{tabular}

Table 3: Comparing mean plantar fasciitis thickness (in $\mathrm{mm}$ ) in the two groups at regular follow up.

\begin{tabular}{|llll|}
\hline Pre-operatively & $\begin{array}{l}\text { Group receiving botulinum toxin } \\
{[\mathbf{n}=\mathbf{2 5}]}\end{array}$ & $\begin{array}{l}\text { Group receiving } \\
\text { corticosteroid [n=25] }\end{array}$ & P value \\
\hline 1 week & $5.67 \pm 0.38$ & $6.06 \pm 0.66$ & 0.14 \\
\hline 3 weeks & $5.65 \pm 0.36$ & $5.81 \pm 0.72$ & 0.34 \\
\hline 3 months & $4.64 \pm 0.56$ & $4.93 \pm 0.39$ & 0.043 \\
\hline 6 months & $4.08 \pm 0.50$ & $4.38 \pm 0.23$ & 0.011 \\
\hline 1 year & $3.73 \pm 0.56$ & $4.13 \pm 0.25$ & 0.003 \\
\hline
\end{tabular}

\section{DISCUSSION}

Although there is no clear consensus on the treatment of plantar fasciitis, it generally accepted that traditional treatment is successful in the majority of cases. Corticosteroid injection is the most preferred option but there is no standardised dose for use indicated in plantar fasciitis. Results of the Cochrane review show that corticosteroid injection therapy has short-term benefit compared to control, and the effectiveness of treatment is not maintained beyond six months. ${ }^{11}$ Botulinum toxin $\mathrm{A}$ is being increasingly used as an alternative treatment to achieve pain relief in patients with plantar fasciitis. ${ }^{12}$ Babcock et al, in a randomized, double-blind, controlled study of 27 patients, reported improvements in the botulinum group with respect to pain relief and overall foot function at 3 and 8 weeks post-treatment. ${ }^{13}$ In another randomized, double-blind study Huang et al injected boltulinum toxin under ultrasound guidance. ${ }^{14}$ The investigators evaluated pain, thickness of plantar fascia and fat pad, foot pressure at 3 weeks and 3 months after treatment in 50 patients with chronic plantar fasciitis. Patients showed improvement in all parameters with botulinum toxin. 
It is unclear whether the therapeutic effect of botulinum in the treatment of chronic plantar fasciitis is due to weakening of muscle or its anti-inflammatory effects. Inflammatory changes are common in plantar fasciitis and local injections with corticosteroids relieve pain in short term. However, its chronic use may result in atrophy of the subcutaneous fat and rupture of the plantar fascia. We did not observe any side effects in either treatment group. Few investigators have explored newer treatment options. Autologous platelet rich plasma is a bioactive component of whole blood with platelet concentration that containing high levels of various growth factors, which can stimulate the reparative process. ${ }^{15}$ Extra-corporeal shock wave therapy has become an increasingly available and popular treatment option for refractory plantar fasciitis, though convincing is limited. ${ }^{16}$

There are a few limitations of this study. Firstly, all patients were advised concurrent exercises and ice application. Confounding may have been introduced due to this as some patients may have used therapeutic exercises more often than others. Secondly, larger sample size and longer follow up period is required to confirm our findings.

\section{CONCLUSION}

Patients of plantar fasciitis who failed conservative management showed better treatment outcomes with botulinum toxin type A as compared to corticosteroids. Under ultrasonographic guidance, injection of both botulinum toxin $\mathrm{A}$ and corticosteroid are safe and effective treatment options for chronic plantar fasciitis. The longer term results and less re-injection rate of botulinum toxin A makes it a more attractive treatment option. However, similar studies need to be replicated with larger sample sizes before this can be offered as a standard treatment for plantar fasciitis patients.

Funding: No funding sources

Conflict of interest: None declared

Ethical approval: The study was approved by the institutional ethics committee

\section{REFERENCES}

1. Hicks JH. The mechanics of the foot, II: the plantar aponeuro- sis and the arch. J Anat. 1954;88(1):2530.

2. Clement DB, Tauton JE, Smart GW, McNicoll KL. A survey of overuse running injuries. Phys Sports Med. 1981;9:47-58.

3. Clement DB, Tauton JE, Smart GW and McNicoll KL. A survey of overuse running injuries. Phys Sportsmed. 1981;9:47-58.

4. Gollwitzer H, Saxena A, DiDomenico LA, Galli L, Bouché RT, Caminear DS, et al. Clinically relevant effectiveness of focused extracorporeal shock wave therapy in the treatment of plantar fasciitis:a randomized, controlled multicenter study. J Bone Joint Surg. 2015;97(9):701-8.

5. Monto RR. Platelet-rich plasma efficacy versus corticosteroid injection treatment for chronic severe plantar fasciitis. Foot Ankle Int. 2014;35(4):313-8.

6. Wheeler P, Boyd K, Shipton M. Surgery for patients with recal- citrant plantar fasciitis: good results at short-, medium-, and long-term follow-up. Orthop J Sports Med. 2014;2(3):2325967114527901.

7. Sammarco GJ, Helfrey RB. Surgical treatment of recalcitrant plantar fasciitis. Foot Ankle Int. 1996;17(9):520-6.

8. Babcock MS, Foster L, Pasquina P, Jabbari B. Treatment of pain attributed to plantar fasciitis with botulinum toxin a:a short-term, randomized, placebo-controlled, double-blind study. Am J Phys Med Rehabil. 2005;84(9):649-54.

9. Torda C, Wolff HG. On the mechanism of paralysis result- ing from toxin of Clostridium botulinum:the action of the toxin on acetylcholine synthesis and on striated muscle. J Pharmacol Exp Ther. 1947;89(4):320-4.

10. Mustafa G, Anderson EM, Bokrand-Donatelli Y, Neubert JK, Caudle RM. Anti-nociceptive effect of a conjugate of sub- stance $\mathrm{P}$ and light chain of Botulinum neurotoxin type A. Pain. 2013;154(11):2547-53.

11. Crawford F, Thomson C. Interventions for treating plantar heel pain. Cochrane Database Syst Rev. 2003;3(3):CD000416.

12. Placzek R, Deuretzbacher G, Meiss AL. Treatment of chronic plantar fasciitis with Botulinum toxin A:preliminary clinical results. Clin J Pain. 2006;22:190-2.

13. Babcock MS, Foster L, Pasquina P, Jabbari B. Treatment of pain attributed to plantar fasciitis with botulinum toxin a:a short- term, randomized, placebo-controlled, double-blind study. Am J Phys Med Rehabil. 2005;84:649-54.

14. Huang YC, Wei SH, Wang HK, Lieu FK. Ultrasonographic guided botulinum toxin type A treatment for plantar fasciitis:an outcome-based investigation for treating pain and gait changes. J Rehabil Med. 2010;42:136-40.

15. Peerbooms JC, Van Laar W, Faber F, Schuller HM, Van Der Hoeven H, Gosens T. Use Of Platelet Rich Plasma To Treat Plantar Fasciitis: Design Of A Multi Centre Randomized Controlled Trial. BMC Musculoskelet Disord. 2010;11:69.

16. Gollwitzer H, Saxena A, DiDomenico LA, Galli L, Bouché RT, Caminear DS, et al. Clinically relevant effectiveness of focused extracorporeal shock wave therapy in the treatment of chronic plantar fasciitis: a randomized, controlled multicenter study. JBJS. 2015;97(9):701-8.

Cite this article as: Samant PD, Kale SY, Ahmed S, Asif A, Fefar M, Singh SD. Randomized controlled study comparing clinical outcomes after injection botulinum toxin type A versus corticosteroids in chronic plantar fasciitis. Int J Res Orthop 2018;4:672-5. 